\title{
Nanotechnical Production and Optimization of Biofuel (Biodiesel) from an Edible Seed Oil (Palm-Olein)
}

\author{
Edmond Moses ${ }^{1^{*}}$, Balan Adamu Thliza ${ }^{2}$ and Buba Usman Shanu ${ }^{3}$ \\ ${ }^{1}$ Department of Chemistry, Modibbo Adama University of Technology, P.M.B. 2076, Yola, \\ Adamawa State, Nigeria. \\ ${ }^{2}$ Department of Chemistry, University of Maiduguri, P.M.B. 1069 Maiduguri, Borno State, Nigeria. \\ ${ }^{3}$ Carbon Scientific Limited White House, Government House Road, Gombe State, Nigeria.
}

Authors' contributions

This work was carried out in collaboration among all authors. All authors read and approved the final manuscript.

Article Information

DOI: $10.9734 / A R R B / 2020 / v 35 i 530222$

Editor(s):

(1) Paola Angelini, University of Perugia, Italy.

Reviewers:

(1) AdefaratiOloruntoba, Nigeria

(2) Alexandre Ricardo Pereira Schuler, Universidade Federal de Pernambuco, Brasil. Complete Peer review History: http://www.sdiarticle4.com/review-history/55139

Original Research Article

Received 01 January 2020

Accepted 04 March 2020

Published 18 June 2020

\section{ABSTRACT}

The synthesized calcium oxide nanoparticles of $24 \mathrm{~nm}$ size from domestic chicken eggshell was used for production of liquid fuel (biodiesel) to test its catalytic behavior, whereas the yield of liquid fuel was also ascertained and it shows varying percentage yields base on different conditions used for the production. The highest yield was found to be $80 \%$ at catalyst concentration of $1.75 \mathrm{ww} \%$ and temperature of $60^{\circ} \mathrm{C}$, followed by $69 \%$ yield at catalyst concentration of 0.5 and temperature of $60^{\circ} \mathrm{C}$, whereas the lowest yield was found to be $58 \%$ which was found to be at the exact catalyst concentration of 0.5 and temperature of $60^{\circ} \mathrm{C}$.

Keywords: Nanotechnology; nanoparticles; biofuel; biodiesel and transesterification.

\section{INTRODUCTION}

\subsection{Nanotechnology}

The emergence of nanotechnology arose out of a convergence of conventional scientific fields, such as physics, chemistry and biology. The word "nano" drives from the Greek word "nanos", which means dwarf and was defined by the Los Alamos National laboratory as the creation of functional materials devices and systems through the control of matter on nanometer $(1-100 \mathrm{~nm})$ 
length scale and the exploitation of real properties and phenomena developed at the scale [1]. A nanometer is one billionth of a meter in length and depending on the size of the atom between three and six atoms will fit inside nanometer $(\mathrm{nm})[1]$.

The essence of nanotechnology is its ability to work at the molecular level and to create structures with fundamentally new molecular organization. When matter is modified at the nanoscale, it acquires new and useful properties not previously created or observed [2].

The physicist, Richard Feynman is widely considered to be the father of nanotechnology (Kale, 2003). In 1959, Feynman suggested that it should be possible to build machines small enough to manufacture realized objects with atomic-level precision. Feynman was with invention by Gerd Binnig and Heinrich Rohrer in [3] of the scanning tunneling microscope (STM) for which they were awarded the novel prize in physics [1]. These were the first tools to allow observation and manipulation of atomic structures and they were basis of the huge advances and the great progress made in nanotechnology [2].

The term nanotechnology was coined and used for the first time in 1974 by the Japanese Scientist, Norio Taniguchi who conceptually explored and developed the idea of nanotechnology in depth in a paper titled "Basic concept of Nanotechnology". He also popularized and accelerated the field through his book titled "Engines of creation" (Singh et al. 2003). He highlighted that nanotechnology mainly consists of processing, separation, consolidation and deformation of materials by one atom or one molecule [4]. Another breakthrough discovery that revolutionized nanotechnology and nanoscience consisted of new carbon shape called carbon nanotube or Bucky balls or Fullerenes (named after Buckminster Fuller). These nanotubes are about 100 times stronger than steel and they have unusual heat and conductivity characteristics which guarantee that they will be important to high technology in feature [1]. Rice University Practice three distinct nanotechnologies: "wet" technology which is the study of biological systems that exist primarily in a water environment. The success of this technology is amply demonstrated by the existence of living organisms whose form, function and evolution are governed by the interactions of nanometer-scale structures. "Dry" nanotechnology derived from surface science and physical chemistry which focuses on fabrication of structures in carbon (fullerenes and nanotubes), silicon and other inorganic materials. Dry techniques admit the use of metals and semiconductors [5-7]. Computational techno-logy permits the modeling and simulation of complex nanometer scale structure. The predictive and analytical power of computation is critical to success in nanotechnology, nature required several hundred million years to evolve functional "wet" technology but the insight provided by computation should allow us few decades' development time of working "dry" technology which will have a major impact on "wet" side as well [4].

Many experts, researchers, engineers, social scientist and policy makers believe that nanotechnology will lead to important changes in the society and that these changes may be of the same magnitude as was the introduction of computers $[8,9]$. This new enabling technology has made it possible to manufacture materials that have not previously existed in our environment and is helping to create a wide range of potentially exciting and innovative applications for environment and other sectors such as medicine, electronics and communication $\quad[10,11]$ Nanotechnology manufactures new materials that present the potential for both positive and negative effects on health and environment. For instance, Nano sensors are high sensitivity detectors of pathogens or pollutants in soil or air $[12,5,6]$. Nanotechnology is expected to play an important role in the remediation of polluted soil and in the development of green manufacturing processes that reduce emissions and wasteful production, reduce the amount of raw materials needed and thus, conserve natural resources [1].

\subsection{Nanoparticles}

One of the first and most natural questions to ask when starting to deal with nanoparticles is why are nanoparticles so interesting? Why even bother to work with these extremely small structures where handling and synthesizing is much more complicated than that of their macroscopic counterparts. The answer lies in the nature and unique properties possessed by nanostructures (Nikolaj, 2005).

Nanoparticles possess a very high surface to volume ratio which can be utilized in areas where high surface areas are critical for success. Mainly 
in catalytic industry; some nanoparticles actually have proven to be good catalyst. Some nanoparticles also show bactericidal effects and here a high surface to volume ratio is also important (Nikolaj et al. 2005).

Nanoparticles are often in the range $10-100 \mathrm{~nm}$, and this is the size as that of human proteins which have attracted much attention in biology and biochemistry. Scientists from the Chinese Academy of Science have suggested using gold nanoparticles to improve Polymerase Chain Reaction (PRC). In the production of antireflective optical coatings, nanoparticles have also proven valuable. Using metal oxides to coat polymeric films, anti-reflective surfaces have been created. Nanoparticles do exhibit many interesting properties, it is just a matter of time until more of these properties will be exploited [13].

Colloidal particles are increasingly receiving attention as important starting points for the generation of micro and nanostructures. These particles are under active research because they possess interesting physical properties differing considerably from that of bulk phase. It comes from small sizes and high surface/volume ratio. Manufacturing entire objects from pure calcium oxide or coating them is prohibitively expensive for consumer items but research has found that impregnating other materials with calcium nanoparticles is a practical way to exploit the germ fighting properties (Nikolaj et al. 2005).

\subsection{Catalyst and Catalysis}

Catalysis is a phenomenon by which chemical reactions are accelerated by small quantities of foreign substances, called catalysts. A suitable catalyst can enhance the rate of a thermodynamically feasible reaction but cannot change the position of the thermodynamic equilibrium. Most catalysts are solids or liquids, but they may also be gases. The catalytic reaction is a cyclic process [14].

According to a simplified model, the reactant or reactants form a complex with the catalyst, thereby opening a pathway for their transformation into the product or products. Afterwards the catalyst is released and the next cycle can proceed. However, catalysts do not have infinite life. Products of side reactions or changes in the catalyst structure lead to catalyst deactivation. In practice, spent catalysts must be reactivated or replaced [14].

\subsection{Biodiesel}

Biodiesel is a clean energy source that can be made from various feedstocks oils such as yellow grease, animal fats, and virgin vegetable oils [15]. It has proven itself as a technically sufficient alternative diesel fuel in the fuel market.

Biodiesel is a biodegradable, sustainable and clean energy source that can be derived from a variety of biomass feedstocks oils such as waste vegetable oil, yellow grease, animal fats, and virgin vegetable oils. It has proven itself as a technically sufficient alternative diesel fuel in the fuel market since the beginning of the 1990s. Biodiesel is defined as a fuel made up of monoalkyl esters of long chain fatty acids derived from vegetable oils or animal fats, designated B100, and meeting the requirements of national fuel specification, American Society for Testing and Materials (ASTM D6751), European norm (EN14214), or its equivalent [16].

There are at least four ways in which oils and fats can be converted into biodiesel, namely, transesterification, blending, micro-emulsions and pyrolysis. Among these, transesterification is the most commonly used method as it reduces the viscosity of oil. Biodiesel is a vegetable oil which can be used in diesel engines after some adjustments and modifications. Vegetable oils are the primary source of biodiesel. They can be of edible or non-edible nature. Edible oils like coconut oil, soybean oil, sesame oil, palm oil, sunflower oil can be used. Non edible oils include algal oil, rubber seed oil, Jatropha carcass, rape seed oil, canola oil etc. In addition to these used oils can also be used for biodiesel production which is more economical. Oils of animal origin derived from sheep and beef tallow, fish oil etc. also serves as source of biodiesel. Vegetable oils contain saturated hydrocarbons (triglycerides) which consist of glycerol and esters of fatty acids. In addition, fatty acids have different numbers of bonds and carbon chain lengths [17]. Biodiesel blends are biodiesel fuel meeting the ASTM D6751 specification blended with petroleum-based diesel fuel designated BXX, where $X X$ is the volume percent of biodiesel (e.g., B20) (Fadhil et al. 2012 and Haas et al. 2006). Biodiesel is produced through several chemical engineering processes but the most common referred to as transesterification, in which a fat or oil is combined with an alcohol and a catalyst to produce an ester (biodiesel, B100) and glycerol [18]. 
Renewable energy sources (RESs) that use indigenous resources have the potential to provide energy services with zero or almost zero emissions of both air pollutants and greenhouse gases. Renewable energy technologies produce marketable energy by converting natural materials into useful forms of energy [19].

\subsection{Edible Vegetable Oils}

Edible vegetable oils are the main sources of biodiesel in all over the world. More than $95 \%$ of global production is made from edible vegetable oils. Global use of edible oils increased with 6.6 million tons between 2004 and 2007, 34\% of this increase is attributed to biodiesel [20]. The most used edible vegetable oils are consecutively rapeseed oil with $59 \%$ of total global biodiesel raw material sources, followed by soybean $(25 \%)$, palm oil $(10 \%)$, sunflower oil $(5 \%)$, and other $(1 \%)$. Studies are taking place in purpose to replace edible vegetable oils with non-edible ones due to the increase in edible oils demands for both food and bio-fuels [21].

Transesterification is converting an alkyl group of an ester to another alkyl group as shown. Transesterification is the reversible reaction of a fat or oil with an alcohol (methanol or ethanol) to form fatty acid alkyl esters and glycerol. It can be alkali-, acid-, or enzymecatalyzed; however, currently the majority of the commercialized technology resides in transesterification using alkali-catalyzed reaction. Mostly, biodiesel is derived from the vegetable oils using sodium or potassium hydroxide catalytic transesterification $[22,23]$.
The transesterification reaction proceeds with catalyst or without any catalyst by using primary or secondary monohydric aliphatic alcohols having 1-8 carbon atoms. The alcohols employed in the transesterification are generally short chain alcohols such as methanol, ethanol, propanol, and butanol. Transesterification reaction is an equilibrium reaction. In this reaction, however, a larger amount of methanol is used to shift reaction equilibrium to right side and produce more methyl esters as proposed product. Ethanol is a preferred alcohol in transesterification reaction compared to methanol because it is derived from agricultural products and is renewable and biologically less objectionable in the environment; however, methanol is preferred because of its low cost and its physical and chemical advantages (polar and shortest chain alcohol) $[24,21]$.

\subsection{Mechanism of $\mathrm{CaO}$ Catalyzed Reaction}

Many different studies reported the reaction mechanism of $\mathrm{CaO}$-catalyzed transesterification, as for example articles of The proposed mechanism is shown in Fig. 2. As shown in Fig. 2. The reaction begins with the attack of a methoxide ion, attached to the catalyst surface, to the carbonyl carbon of the triglyceride molecule to form a tetrahedral intermediate. In the second step, the unstable tetrahedral intermediate is rearranged and broken down to diglyceride anion and fatty acid methyl ester. Thediglyceride anion is then stabilized by a proton from the catalyst surface to form

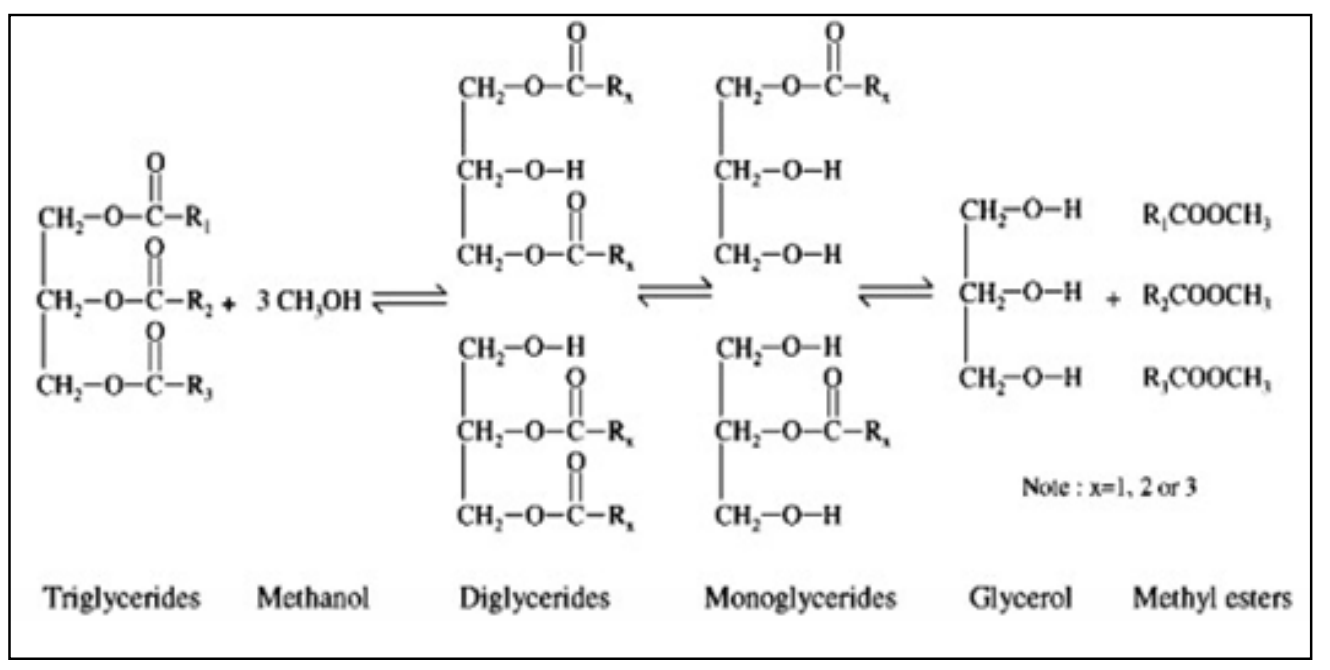

Fig. 1. Reactions in the transesterification of a triglyceride[25] 
diglyceride and at the same time the active site at the catalyst surface is regenerated. Then, the methoxideanion attacks on another carbonyl carbon atom in diglyceride, forming another mole of methyl ester and monoglyceride [26].

These three steps are repeated until all three carbonyl centers of the triglyceride have been attacked by the methoxide ions to give one mole of glycerol and three moles of methyl esters. According to results of different investigations reported in literature the first and second step of complex process (reaction of triglyceride and methanol and formation of diglycerides and FAME, as well as, reaction of diglycerides with methanol in which monoglycerides and FAMEs are formed) are always much faster than reaction of monoglycerides and methanol producing the final amount of FAME and glycerol [27].

\section{MATERIALS AND METHODS}

Reactor, beakers, weighing balance, funnel and separating funnel, $\mathrm{pH}$ meter, heating mantle. Some of the reagents that were used includes; distilled water, sodium sulphate, sulphuric acid, methanol, sodium sulphate. Deionized water, stirrer, measuring cylinder, ware obtained from the Northern Scientific Chemical Store Jimeta Yola.

\subsection{Equipment}

Gas Chromatography, Batch reactor are the machines used for the analysis and the software Design Expert Version 12 was used for the analysis of the variance and optimization of the result of the analysis.

\subsection{Sample Location}

Palm-Olein was collected from Gaanda Township Market in Gombi Local Government Area of Adamawa State Nigeria and was kept at room temperature, this is a method adopted from Nijuet al.[28].

\subsection{Sample Preservation}

The sample was collected in a container and preserved according to the standard method of American Public Health [29].

\subsection{Quality Assurance}

All reagents used were of pure analytical grade. Contamination was thoroughly checked by running a blank of all determinations. Glass apparatus used during the production of Biodiesel were soaked in a clean soap solution and in $\mathrm{H}_{2} \mathrm{SO}_{4} / \mathrm{HNO}_{3}$ mixture, rinsed with distilled water and was dried in an oven for 30 min [28].

\subsection{Esterification Procedure for the Pretreatment of the Oil}

First, free fatty acid (FFA) of the crude palm oil was reduced by an acid-catalyzed esterification process. The esterification process was done under the following conditions; oil to alcohol molar ratio $=10: 1$, volume of acid $\left(\mathrm{H}_{2} \mathrm{SO}_{4}\right)=13.40$ $\mathrm{cm}^{3}$, time of reaction $=90 \mathrm{~min}$, and temperature $=60^{\circ} \mathrm{C}$. The application of these conditions drastically reduce the Free Fatty Acid (FFA) of the palm oil which made it easier and favorable for further transesterification process. For the

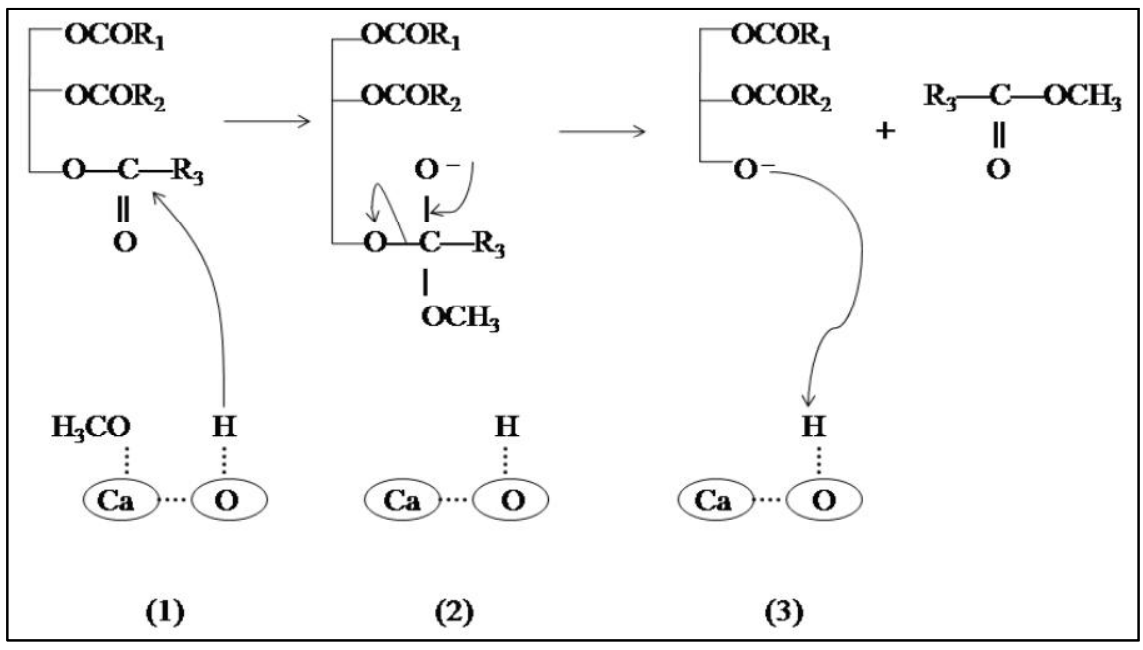

Fig. 2. Mechanism of CaO-catalyzed transesterification[30] 
transesterification, 10 Runs ware transesterified under different conditions as can be seen in Table 1 below. The 10 runs were transesterified separately and GC analysiser was used to determine the yield of each run.

\subsection{Separation and Purification Biodiesel}

The biodiesel produced was first subjected to natural gravitational settling overnight and the two distinct layers (biodiesel and glycerol) were formed and are separated via simple decantation process of separation. As earlier mentioned, this is because there is a distinct density difference between biodiesel and glycerol, glycerol being denser than the biodiesel settles below the biodiesel and also there are differences in their polarities where biodiesel is hydrophobic and glycerol being hydrophilic made their separation faster and easier. The residual methanol was separated using heating mantle equipment with constant stiring by evaporation at a temperature of $70^{\circ} \mathrm{C}$ and time: $30 \mathrm{~min}$. However, biodiesel still contain traces of impurities that needed to be removed for the biodiesel produced to attain ASTMD6751 and EN14214. Therefore, to achieve this, water washing was carefully performed.

\section{RESULTS AND DISCUSSION}

\subsection{Analysis of Biodiesel}

The yields of biodiesel samples in Table 1.were analyzed by a HP 6890 Gas Chromatogram (GC) equipped with a Flame Ionization Detector (FID) and capillary column DB23 $(60-\mathrm{m} \times 0.25 \mathrm{~m} \times 0.15$ $\mu \mathrm{m}$ ) according to a methodology proposed by Agilent ASTM, [8].

\subsection{Data Analysis}

The statistical analysis of variance (ANOVA) was carried out using the software (Design-Expert 12 software - the latest version (Stat-Ease Inc., USA) so as to evaluate the precision, the fitness and the significance of the model, the effects of the individual parameters and interaction effects on the response. In addition, Catalyst concentration $A$, Ethanol to Oil molar ratio Band the reaction temperature $\mathrm{C}$, reaction temperature - catalyst concentration interaction, CA, and the interaction term of molar ratio - catalyst concentration, BA, were significant model terms with the lack of fit is regarded as the weighted sum of squared deviations between the mean response at each factor level and the corresponding fitted value. In this research work the lack of fit is not significant for the response with a P-value of 0.0500 (lack of fit is 11); this indicates that the model is fitted to all data (Notsignificant, lack of fit is good). Adequate precision is a measure of signal to noise ratio; it compares the range of the predicted values at the design points to the average prediction error and as prerequisite of the model, a ratio of greater than 4 is desirable. In this model, the ratio of 13.058 indicates sufficient model discrimination.

\subsection{Development of Regression Model Equation}

The complete design matrixes together with both the experimental as well as predicted values obtained for yield response at the design points are shown in Table 1 . The runs at the centerpoints were used to determine the experimental error. Biodiesel yield obtained ranged from $58.00 \%$ to $80.00 \%$. A polynomial

Table 1. Yields of Biodiesel (Two-step transesterification)

\begin{tabular}{lllll}
\hline & Factor $\mathbf{1 .}$ & Factor 2. & Factor 3. & R.1. \\
\hline Runs & A:Cat.con. & B:M.R & C:Temp. & Yield. \\
\hline & (w/w\%) & - & $\left({ }^{\circ} \mathbf{C}\right)$ & (\%) \\
\hline 1 & 0.5 & 6 & 50 & 65 \\
2 & 0.5 & 10 & 50 & 68 \\
3 & 1.75 & 8 & 55 & 76 \\
4 & 1.75 & 8 & 55 & 76 \\
5 & 1.75 & 8 & 60 & 80 \\
6 & 3 & 8 & 55 & 58 \\
7 & 0.5 & 6 & 60 & 59 \\
8 & 3 & 6 & 50 & 60 \\
9 & 0.5 & 10 & 60 & 69 \\
10 & 1.75 & 8 & 55 & 76 \\
\hline
\end{tabular}


regression equation was developed by using CCD coupled with RSM to analyze the factor interactions by identifying the significant factors contributing to the regression model. DesignExpert software (version 12) fitted four models to the response: linear, two factor interaction (2FI), quadratic and cubic polynomials. According to the sequential model sum of squares, the best model was selected based on the highest order polynomial where the additional terms were significant and the model was not aliased.

In Table 3, all the leverages can be seen at ranges of 0.05 to 0.30 , non of the leverages is even a half of 1.0. This shows a good product as a result of careful procession. For leverages close to 1.0, it will be considered replicating the points or make sure they are run very carefully.

\section{Build Information}

\begin{tabular}{llll}
\hline File Version & 12.0 .0 .6 & & \\
Study Type & Response Surface & Subtype & Randomized \\
Design Type & Central Composite & Runs & 10 \\
Design Model & Quadratic & Blocks & No Blocks \\
Build Time $(\mathrm{ms})$ & 7.00 & & \\
\hline
\end{tabular}

Table 2. Factors

\begin{tabular}{llllllllll}
\hline Factor & Name & Units & Type & Min. & Max. & Coded Low & Coded High & Mean & $\begin{array}{l}\text { Std. } \\
\text { Dev. }\end{array}$ \\
\hline A & Cat.con & $($ w/w\%) & Numeric & 0.50 & 3.00 & $-1 \leftrightarrow 0.50$ & $+1 \leftrightarrow 3.00$ & 1.75 & 0.98 \\
B & Molar ratio & - & Numeric & 6.00 & 10.00 & $-1 \leftrightarrow 6.00$ & $+1 \leftrightarrow 10.00$ & 8.00 & 1.45 \\
C & Temp & ${ }^{\circ} \mathrm{C}$ & Numeric & 50.00 & 60.00 & $-1 \leftrightarrow 50.00$ & $+1 \leftrightarrow 60.00$ & 55.00 & 3.63 \\
\hline
\end{tabular}

Table 3. Leverage

\begin{tabular}{lll}
\hline Run & Leverage & Space Type \\
\hline 1 & 0.35 & Factorial \\
2 & 0.35 & Factorial \\
3 & 0.05 & Center \\
4 & 0.05 & Center \\
5 & 0.15 & Axial \\
6 & 0.15 & Axial \\
7 & 0.35 & Factorial \\
8 & 0.35 & Factorial \\
9 & 0.35 & Factorial \\
10 & 0.05 & Center \\
\hline
\end{tabular}

Table 4. ANOVA for quadratic model

Response 1: Yield

Transform: Natural Log

Constant: 0

\begin{tabular}{llllll}
\hline Source & Sum of Squares & df & Mean square & F-value & p-value \\
\hline Model & 0.23 & 9 & 0.0223 & 9.67 & 0.0007 \\
\hline A-Cat.con & 0.0194 & 1 & 0.0194 & 8.41 & 0.0158 \\
B-Molar ratio & 0.0054 & 1 & 0.0054 & 2.34 & 0.1570 \\
C-Temp & 0.0006 & 1 & 0.0006 & 0.2473 & 0.6297 \\
AB & 0.0069 & 1 & 0.0069 & 2.99 & 0.1143 \\
AC & 0.0028 & 1 & 0.0028 & 1.20 & 0.2998 \\
BC & 0.0016 & 1 & 0.0016 & 0.6812 & 0.4284 \\
$A^{2}$ & 0.0460 & 1 & 0.0460 & 19.97 & 0.0012 \\
$B^{2}$ & 0.0391 & 1 & 0.0391 & 16.98 & 0.0021 \\
$C^{2}$ & 0.0152 & 1 & 0.0152 & 6.61 & 0.0278 \\
Residual & 0.0230 & 10 & 0.0023 & - & - \\
Lack of Fit & 0.0230 & 5 & 0.0046 & - & - \\
Pure Error & 0.0000 & 5 & 0.0000 & - & - \\
Cor Total & 0.2234 & 19 & & - & - \\
\hline
\end{tabular}


From Table 4, the coefficient estimate represents the expected change in response per unit change in factor value when all remaining factors are held constant. The intercept in an orthogonal design is the overall average response of all the runs. The coefficients are adjustments around that average based on the factor settings. When the factors are orthogonal the VIFs are 1 ; VIFs greater than 1 indicate multicolinearity, the higher the VIF the more severe the correlation of factors. As a rough rule, VIFs less than 10 are tolerable.

\subsection{Final Equation in Terms of Coded Factors}

The equation in terms of coded factors can be used to make predictions about the response for given levels of each factor. By default, the high levels of the factors are coded as +1 and the low levels are coded as -1 . The coded equation is useful for identifying the relative impact of the factors by comparing the factor coefficients.

\section{Final Equation in Terms of Actual Factors}

\begin{tabular}{ll}
\hline $\ln ($ Yield $)$ & $=$ \\
+11.76809 & \\
+0.185068 & Cat.con \\
+0.431993 & Molar ratio \\
-0.342253 & Temp \\
-0.011738 & Cat.con * Molar ratio \\
+0.002968 & Cat.con * Temp \\
+0.001400 & Molar ratio * Temp \\
-0.082735 & Cat.con ${ }^{2}$ \\
-0.029803 & Molar ratio $^{2}$ \\
+0.002976 & Temp $^{2}$ \\
\hline
\end{tabular}

The equation in terms of actual factors can be used to make predictions about the response for given levels of each factor. Here, the levels should be specified in the original units for each factor. This equation will not be used to determine the relative impact of each factor because the coefficients are scaled to accommodate the units of each factor and the intercept is not at the center of the design space.

To ascertain the reliability of the model, the data achieved predicted with reasonable accurateness by the model in comparison with the experimental data. Table 4 represents the predicted and the experimental value for the twosteps transesterification process using the developed model equation. At these conditions, the biodiesel yield almost meets the specified by EN 14214 (96.245\%).

\subsection{Influence of the Parameters Ester Yields on the Methyl}

Based on the developed models, it was observed that all the three parameters (A, B, and C) played a vital role during the production of biodiesel via two-steps transesterification. For Fig. 4 (a) and (b), it can be shown that, at $55-57^{\circ} \mathrm{C}$ reaction temperatures, the amount of methyl ester yields increased with the same reaction time. However, low biodiesel yields were recorded at temperatures of $60^{\circ} \mathrm{C}$, which could be attributed to the volatility of methanol as it approaches its boiling point. It is worthy to mention that high biodiesel yields were achieved at a reaction time of $70 \mathrm{~min}$.

For Fig. 3 (a) and (b), it can be seen that the effect of differing catalyst concentration and time on the synthesis of biodiesel is considerable. At high catalyst concentration of $2.9 \mathrm{ww} \%$, synthesis of biodiesel was slightly low; this could be attributed to some catalyst be consumed via process of saponification.

From the Fig. 4(a and $b)$ is a three dimension (3D) response surface presentation of the effects of molar ratio and catalyst concentration (ww\%) on the yield of liquid fuel product. An increase in biodiesel yield due to the fact that the quadratic terms of the two factors $B$ and $A$, ie molar ratio and catalyst concentration respectively are very significant with a positive effect.

At a low catalyst concentration, there is a considerable increase in the percentage amount of the liquid fuel (biodiesel) with the molar ratio as a result of the positive effect of $A$ and $B$. Conversely, there is a drop on the percentage yield of the biodiesel as can be seen at around the molar ratio of $2: 8$. There is also a significant drop of the percentage yield at the molar ratio of around $2: 9 w w \%$ to $69 \%$. It can also be seen that the percentage yield of the product drastically drops to $59 \%$ as the catalyst concentration increases from $1.7 \mathrm{ww} \%$ through $3.00 \mathrm{ww} \%$. In general, the serial drop of the percentage yield of the biodiesel with increase in catalyst concentration could be attributed to catalyst consumption and transformation in to soap and glycerine. 


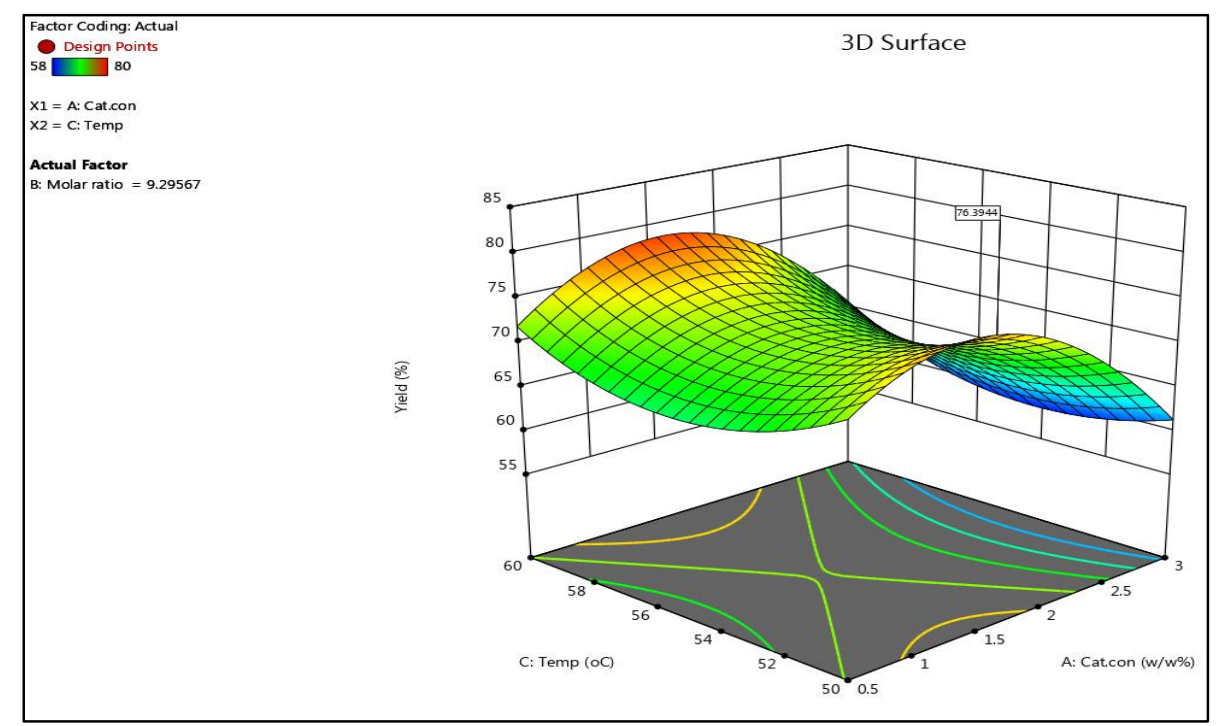

Fig. 3a. Plots (3D) for Response surface presenting the effects of temperature $\left({ }^{\circ} \mathrm{C}\right)$ and catalyst Concentration (\%) on the yields of biodiesel

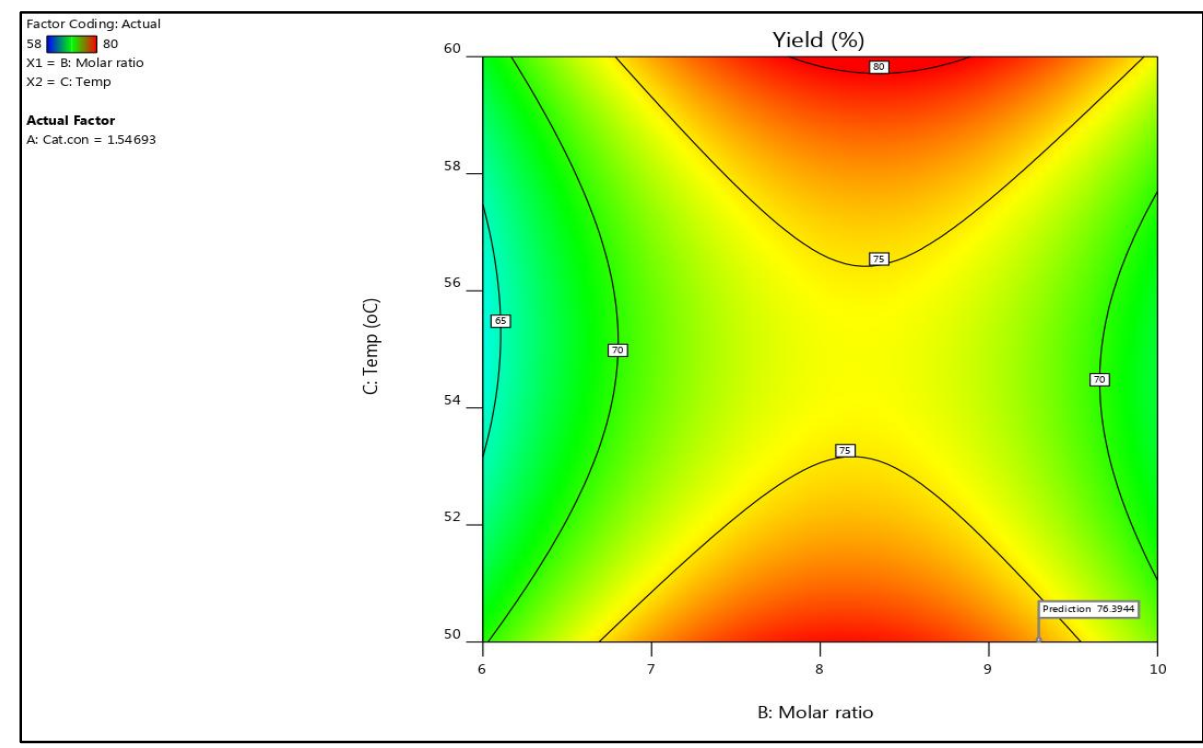

Fig. 3b. Plots (2D) for Response surface presenting the effects of temperature $\left({ }^{\circ} \mathrm{C}\right.$ ) and catalyst Concentration (\%) on the yields of biodiesel

Fig. $3 a$ is the $3 \mathrm{D}$ response surface presentation of the effect of temperature $\left({ }^{\circ} \mathrm{C}\right)$ and catalyst concentration (ww \%) on the product percentage yield of the liquid fuel (biodiesel). A high percentage yield was recorded at the moderate temperature of $56^{\circ} \mathrm{C}$ while a lower percentage yield of $50 \%$ was recorded at the catalyst concentration of 2.0 ww \%. This could be attributed to the fact that at low temperature, the catalytic activity is very low and was unable to react very well and at high temperature, there is an evaporation of the alcohol leaving just a small amount of the alcohol (methanol) for the reaction.

Fig. $3 b$ is a two-dimension contour (2D) representing the effects of catalyst concentration and temperature on the percentage yield of the liquid fuel (biodiesel).

Fig. $4 a$ and $b$ are the response surface presentation of the effect of temperature $\mathrm{C}\left({ }^{\circ} \mathrm{C}\right)$ and molar ratio $B$ on the percentage yield of the 
liquid fuel (biodiesel). It shows the effect of differing two process parameters in production of liquid fuel (biodiesel). The highest percentage yield of the whole process parameters of $80 \%$ was recorded at a moderate temperature of $55^{\circ} \mathrm{C}$ at the molar ration of methanol to oil ratio of $2: 6$ at constant time of $70 \mathrm{~min}$. There is a considerable drop of the percentage yield of the biodiesel as the molar ratio of the methanol to oil increases to $2: 9$ and this could be attributed to evaporation of the methanol as the temperature increase.

Fig. $4 \mathrm{~b}$ is the two dimension (2D) contour from the shadow of response surface presentation of the effect of temperature $C$ and molar ratio $B$ on the percentage yield for the production of liquid fuel (biodiesel).

\subsection{Process Optimization}

There are abundant technologies obtainable for the optimization of chemical processes. Based on the predicted models, numerical hill-climbing algorithms were employed to seek for the most desirable outcome Numerical optimization provides up-to-date and a complete description of the most effective methods in continuous optimization. It responds to the growing interest in optimization in business, science, and engineering by focusing on the technologies that are most suited to practical problems. Thus the optimization process was performed based onthelimits of parameters on Table 4 and response generated for the transesterification. Atthese optimum points, the value of biodiesel

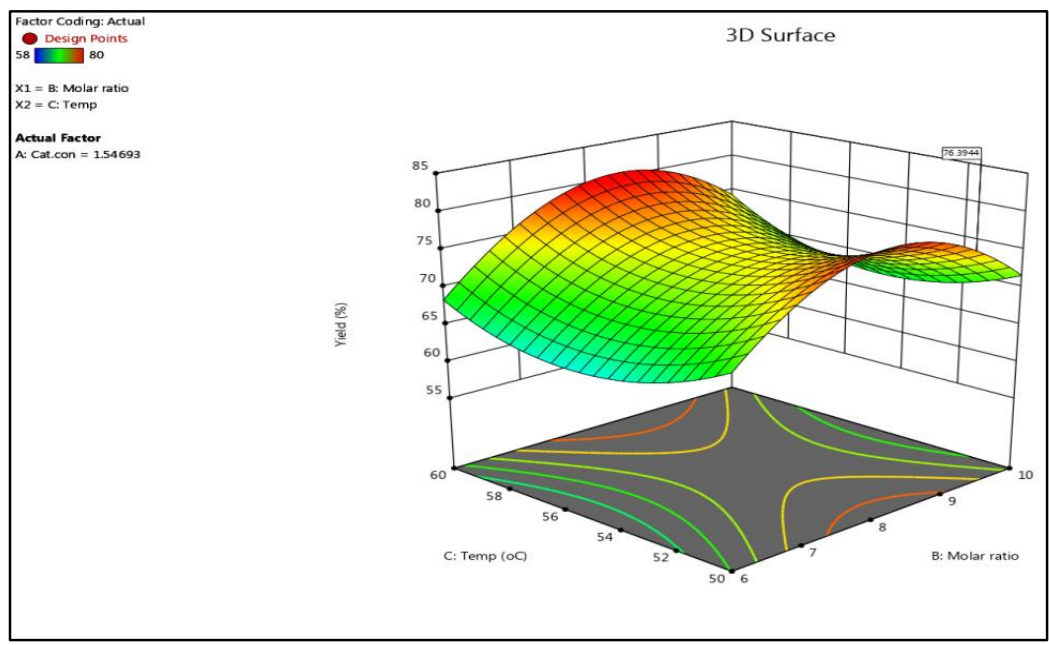

Fig. 4(a). Plots (3D) for Response surface presenting the effects of temperature and molar ratio), on the yield of biodiesel

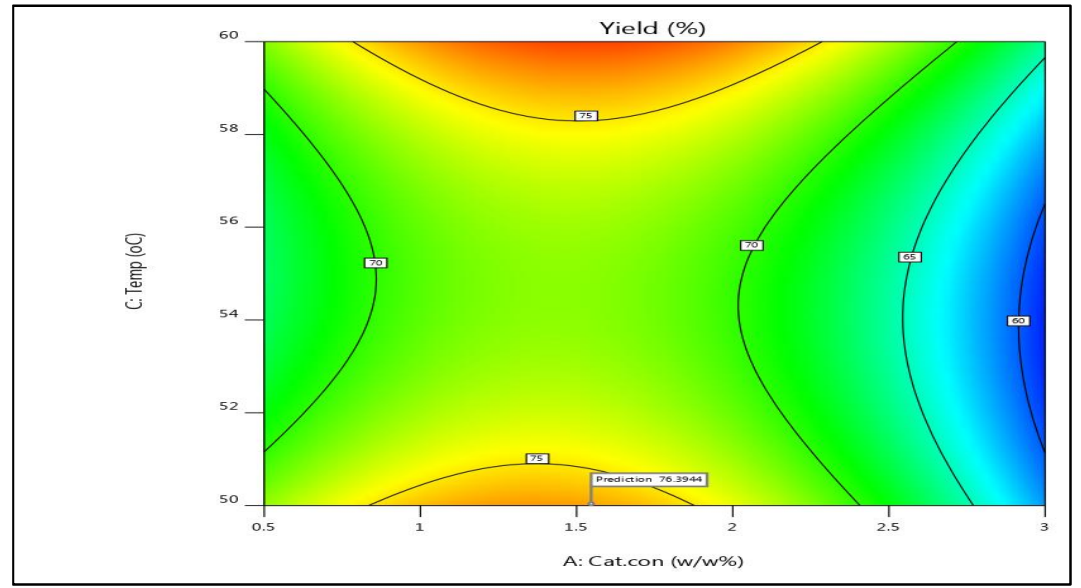

Fig. 4b. Plots (2D) for Response surface presenting the effects of temperature and molar ratio), on the yield of biodiesel 
yields almost meets the condition specified by EN 14214 (96.00\%). Good agreement between the results achieved for the experimental and predicted values established the validity of the models and the existence of the optimum condition. Further the accuracy of the models can be further justified by the statistical fits presented in Table 4. In addition, the results obtained demonstrated that Response Surface Methodology (RSM) with appropriate design of experiment can be successfully applied for the optimization of the parameters in a production process. Therefore, this study is centered on the application of RSM to optimize biodiesel yield via two-step heterogeneous-catalyzed transesterification reaction. The optimization process may present valuable information pertaining to the development of efficient and economic processes for the production of biodiesel using transesterification process.

\section{CONCLUSION}

Nanotechnical production of liquid fuel using the heterogeneous catalyst (calcium oxide) nanoparticles by Two-steps method of production of liquid fuel (Biodiesel) was also performed. The process parameters of the yield of liquid fuel (Biofuel) such as molar ratio, temperature and concentration were also checked and characterization of physical properties of the biodiesel in order to the optimum conditions of the production.

Acid catalyzed - esterification was carried out on the crude palm - olein in other to reduce the level of free fatty acid to a level that will ease the production for a higher percentage yield. To this effect, $3 \%$ tetraoxosulphate vi acid was effective for reducing the free fatty acid.

High biodiesel yield of $80 \%$ was obtained after transesterification reaction with the synthesized $\mathrm{CaO}$ nanoparticle. The methyle ester yield of $80 \%$ is around the value stipulated by European Norm (EN) 14214 (96.5\%).

\section{COMPETING INTERESTS}

Authors have declared that no competing interests exist.

\section{REFERENCES}

1. Bergeron S, Archambault E. Stewardship in nanotechnology for environment. Environmental Biotechnology Application
Division Technology and Industry Brach. 2005;1-7.

Available:Canada.info@science.mextrixco

$\mathrm{m}$

2. Choi KH. Ethical issues of nanotechnology development in Asia- Pacific Region. UNESCO. 2003;327-376.

3. Binnig G, Rohrer H, Gerber C, Weibel E. Surface studies by scanning tunneling microscopy. Physical review letters.1982;49(1):57.

4. Singh M, Singh S, Prasad S, Gambhirl S. Nanotechnology in medicine \& antibacterial effect of Silver nanoparticles. Digest Journal of Nano materials and Biostructures. 2008;3(3):115-122.

5. Nicolai Bityutski, Polina Kaidun, Kirill Yakkonen. Can earthworm alleviate nutrients disorder of plants substance to to calcuim carbonate excess. Applied Soil Ecology. 2016;98:20-29.

6. Singh DK, Pandey DK, Yadav RR, Singh $\mathrm{D}$. A study of $\mathrm{ZnO}$ nanoparticles and $\mathrm{ZnO}-$ EG nanofluid. Journal of Exploration of Nano-science. 2013;8:567-577.

7. Singh N, Jenkins GJS, Asadib R, Doak $\mathrm{SH}$. Potential toxicity of superparamagnetic iron oxide nanoparticles (SPION). Nanotechnology Reviews. 2010; 1:5358.

8. ASTM D2234-98: Standard practice for collection of a gross sample of coal. In Annual Book of ASTM Standards; ASTM International: West Conshohocken. 1998; 262-272.

9. Choi WJ, Hartono MR, Chan WH, Yeo SS. Ethanol production from biodiesel-derived crude glycerol by newly isolated Kluyvera cryocrescens. Applied Microbiology and Biotechnology. 2011;89:1255-1264.

10. Baroutian S. A packed bed membrane reactor for production of biodiesel using activated carbon supported catalyst', Bioresource Technology. 2011;102(2): 1095-102.

11. Kaler A, Patel N, Banerjee UC. Green synthesis of silver particles: Current Research Information on Pharmaceutical Science (CRIPS) @ NIPER, SAS Nagar India CRIPS. 2010;11(4):68-71.

12. Mathiesen J, Wendt $S$, Hensen J, Besenbacher F. Obsavation of intermediate steps of chemical reaction on an oxide surface by Scanning Turnelling Microscore; 2011.

13. Ratyakshi, Chauhan RP. Colloidal synthesis of silver nanoparticles. Asian 
Journal of Chemistry. 2009;21(10):113116.

14. Lund $\mathrm{H}$, Mathiesen BV. Energy system analysis of $100 \%$ renewable energy systems-The case of Denmark in years 2030 and 2050. Energy. 2009;34(5): 524531.

15. Baroutian S, Aroua MK, Raman AA, Sulaiman NM. Viscosities and densities of binary and ternary blends of palm oil+ palm biodiesel+ diesel fuel at different temperatures. Journal of Chemical \& Engineering Data. 2010;55(1); 504-507.

16. Edmond $M$. One-step production of Biodiesel from Crude Palm Oil planted in Gaanda using Methanol, Adamawa State Nigeria. Journal of Engineering and Scientific Research. 2018;5(6):67-68.

17. Huda Muhammad Badrul, Nuryanto Rahmat, Suhandono Steven, Fadhilah Syarifah, Wiarsih Shelly and Prakoso Fiky Agung. Synthesis and characterization of nano calcium oxide from eggshell to be catalyst of biodiesel from waste oil. 2014; 421-422.

18. Ghotli RA, Aziz ARA, Atadashi IM, Hasan DB, San Kong P, Aroua MK. Selected physical properties of binary mixtures of crude glycerol and methanol at various temperatures. Journal of Industrial and Engineering Chemistry. 2015;21:10391043.

19. Singh Bhaskar. Towards a sustainable approach for development of biodiesel from plant and microalgae', Renewable and Sustainable Energy. Reviews. 2014; 29:216-45.

20. Leung DY, Wu X, Leung MKH. A review on biodiesel production using catalyzed transesterification. Applied energy. 2010; 87(4):1083-1095.

21. Manuale DL, Greco E, Clementz A, Torres GC, Vera CR, Yori JC. Biodiesel purification in one single stage using silica as adsorbent. Chemical Engineering Journal. 2014;256:372-379.

22. Atadashi IM. Purification of crude biodiesel using dry washing and membrane technologies. Alexandria Engineering Journal. 2015;54(4):1265-1272.

23. Avinash KA. Biofuels (alcohols and biodiesel) applications as fuels for internal combustion engines', Progress in Energy and Combustion Science. 2007;33(3):23371.

24. Luonsi A. Separation of CTMP millactivated sludge with ceramic membranes', Desalination. 2002;146(1-3):399-404.

25. Abdullah AZ, Razali N,Mootabadi $H$, Salamatinia B. Critical technical areas for future improvement in biodiesel technologies', Environmental Resources Lett. 2. 2007;1-6.

26. Željka Kesic, Ivana Lukic, Miodrag Zdujic, Ljiljana Mojovic, Dejan Skala. Calcium oxide based catalyst for Biodiesel production: A Review. Journal of Chemical Industry \&Chemical Engineering. 2016; 22(4):391-408.

27. Demirbas A. Progress and recent trends in biodiesel fuels. Energy Convection Management. 2009;50:14-34.

28. Niju S, Anantharaman N. The modification of egg-shell and its application in Biodiesel production. Journal of Engineering and Scientific Research. 2014;4(2):2324.

29. American Public Health Association. APHA 2009 agenda for health reform; 2009.

30. Oliver N. Maitera, Edmond Moses, Dass PM. Production of biodiesel using calcium oxide $(\mathrm{CaO})$ Nanoparticle synthesized from chicken eggshell. International Journal of Progressive Sciences and Technologies (IJPSAT); 2019.

ISSN: 2509-0119.

(c) 2020 Moses et al.; This is an Open Access article distributed under the terms of the Creative Commons Attribution License (http://creativecommons.org/licenses/by/4.0), which permits unrestricted use, distribution, and reproduction in any medium, provided the original work is properly cited.

Peer-review history:

The peer review history for this paper can be accessed here: http://www.sdiarticle4.com/review-history/55139 